\title{
Formulating Strategies Towards Economic and Technological Retrofitting of Macrosocial Systems
}

\author{
Lilia Aubakirovna Enikeeva \\ Doctor of Science, professor of The Operations Research in Economics Department (Professor Y.Lvov Department), \\ Saint-Petersburg State University of Economics, Sadovaya, 21 St. Petersburg \\ Enikeeva_lilia@mail.ru

\section{Elena Konstantinovna Torosyan}

Ph.D., assistant professor at the Department of Economics and Strategic Management, Saint- Petersburg National Research University of Information Technologies, Mechanics and Optics, 49 Kronverksky Pr. St. Petersburg etorosyan@mail.ru

\section{Doi:10.5901/mjss.2015.v6n4s3p637}

\section{Abstract}

Uneven economic development of individual countries and their lagging behind the developed economies in terms of the economic growth rate, which include Russia, have a direct impact on the structural changes in the macrosocial systems, and require formulating new strategies as part of the structural and cyclic retrofitting paradigm of macrosocial systems. Studies into macrosocial systems should consider that they are not only complex, but also dynamic, and apt for cyclicality and transformation. This article focuses on the macrosocial system transformation mechanisms in the context of the global crisis. Based on this, the article also looks at the possibilities of achieving inner resilience to significant macro-scale institutional changes through achieving a balance of institutional mechanisms of self-regulation and public regulation. Particular attention is paid to the measurement of structural shifts, which is relevant in the conditions of cyclic fluctuations and convergence of macrosocial systems. Sources in the article have been research materials prepared under Russian Science Foundation grant No. 14-28-00065.

Keywords: structural and cyclic paradigm, economic and technological retrofitting, macrosocial system, dynamic of the sectoral structure, technological structure of the manufacturing industry.

\section{Introduction}

In the context of global instability, it is becoming particularly essential to formulate structural and cyclic paradigms for the economic and technological retrofitting of macrosocial systems.

According to A. Martynov, issues confronted by large macrosocial systems which include groups of states and the entire world community, reduce to issues of specific countries - of national communities. At any rate, it is the parameters of their state that primarily serve as indicators for the state of the globalized world community and its constituent parts. (Martynov, 2006). This view is currently predominant.

The nature of the economic reality reveals that the existing general scientific paradigm (the theory of selforganization, synergy) is still unable to provide adequate methods of its study (Martynov, 2002). Macro-social systems are by several orders of magnitude more complex - it is not only self-organization of the system consisting of selforganized elements.

No answers are suggested to questions about the causes and patterns both in drastic structural changes and minor changes - fluctuations and mutations of macrosocial systems. Although economic theory is able to obtain impressive results by utilizing the existing general scientific paradigm, the issues of economic and technological retrofitting of macrosocial systems are scarcely explored and examined in detail.

In our opinion, the approach of Friedrich Hayek also appears controversial. According to it, society will have to increasingly rely on the self-regulation and self-organization mechanisms without trying to improve them using imperfect management tools (Hayek, 1991).

Based on the current situation, it is more appropriate to speak of the possibilities of ensuring a macrosocial system's inner resilience to significant macro-scale institutional changes through building a harmonious unity of 
institutional mechanisms of self-regulation and public regulation.

The use of the institutional approach is also favored by the fact that the principles of equality, sovereignty, and at the same time of interdependence of various social institutions in a macrosocial system are characterized by patterns of their formation (Martynov, 2006).

The point at issue is about the strengthened role of the underlying institutional practices of public regulation in the form of economic and technological retrofitting of macrosocial systems compared to the alternative self-regulation practices.

We agree with Barashov 2010, that special emphasis should also be put on the measurement of structural shifts, which is important in the conditions of cyclic fluctuations and convergence macrosocial systems (Barashov, 2010).

\section{Material and Methods}

In this article, we use the example of the Russian macrosocial system and its economic and technological improvement to define the role and place of formulating strategies towards economic and technological retrofitting of macrosocial systems.

The key approaches include the systems approach and institutional approach, which have been actively used by Russian and foreign researchers, as well as methods (retrospective, scientific abstraction, comparative analysis, economic and statistical method) to develop strategies towards economic and technological retrofitting.

The work is based on materials and data prepared under Russian Science Foundation grant No. 14-28-00065 and published sources.

The integrated use of the materials and sources will help fulfill the stated objectives.

\section{Results}

An analysis of the dynamic of Russia's sectoral and technological structure showed that developing a methodology of modeling strategies towards qualitative and quantitative evaluations of structural changes is of strategic importance for the development of Russia's national economy.

Assessing quality of sectoral and technological structures makes it possible to determine the nature of changes in the state of macrosocial systems and their constituent parts.

Institutional reforms are needed to strike a balance between institutional mechanisms of self-regulation and public regulation.

Prioritized public funding plays a role of a public regulator designed to optimize structural and technological shifts in the Russian economy (high technology and medium high technology sectors).

The macrosocial system and its individual subsystems require a transition to an innovative, socially-oriented type of self-development.

Keeping macrosocial systems stable involves formulating strategies towards their economic and technological retrofitting as a structural and cyclic paradigm for crisis developments.

The economic and technological updates in macrosocial systems are possible using harmonized material and nonmaterial components in structural and technological innovations that affect the economic growth and well-being of the population.

\section{Discussion}

The data analysis of trends in the sectoral structure of the added value in Russia's GDP, shown in Figure 1, suggests that the change in the structure is resulting from the reduced share of processing industries and agriculture, and growing share of the service sector. 


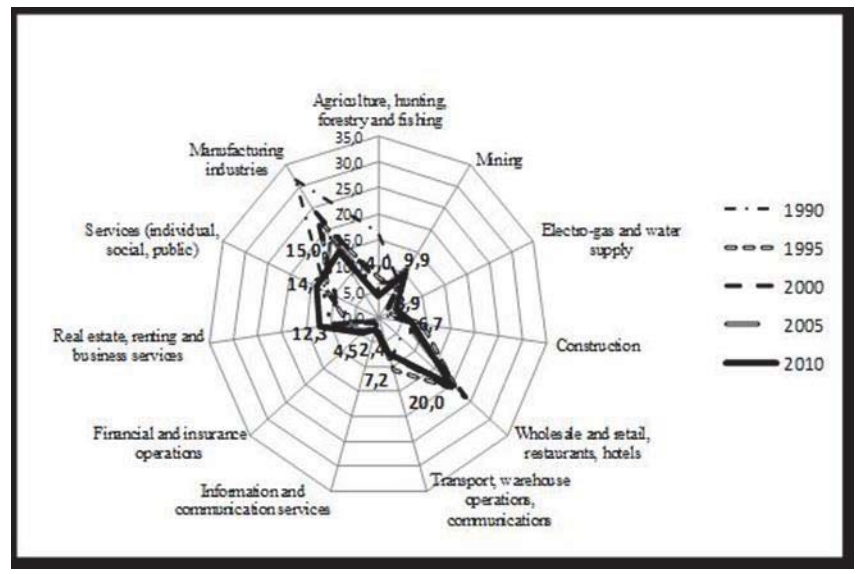

Figure 1. Trends in the sectoral structure of the added value in Russia's GDP (\%\%) Data source: (Akayev, 2013)

According to the classification adopted by the European Union (EU), the four levels of technological development of Russia's manufacturing industry, represented in Figure 2, characterize structural shifts towards a bigger share of high technology and smaller share of medium high technology sectors.

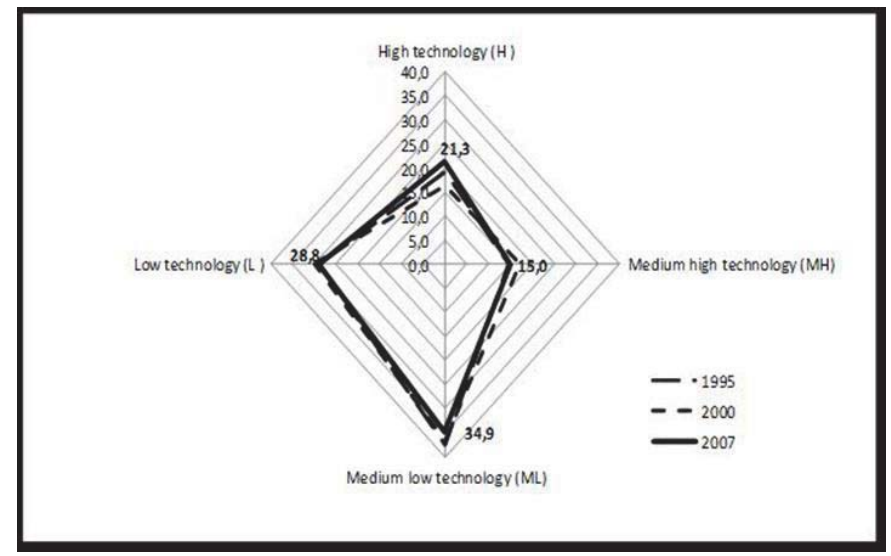

Figure 2. Trends in the technological structure of Russia's manufacturing industry (\%)

Data source: (Akayev, 2013)

For Russia, this means that the manufacturing industry is beginning to enjoy technological modernization with its changing sectoral structure and declining share in the added GDP value.

At the moment, it needs efficient structural and technological policies from the government, which can greatly enhance the innovative activity of the private sector.

The public funding priority areas designed to optimize the structural and technological shifts in today's Russian economy may include high technology and medium high technology sectors.

The advanced structural and technological shifts are possible based on the further development of the following: information and communication technologies (ICT), scientific and innovation sectors (research and development sectors in air and spacecraft manufacturing, television and radio transmitters, equipment for cable telephony and telegraph communications, pharmaceutical products). The medium high technology sector offers a long term potential in the areas such as machinery and equipment, transportation means (incl. automotive industry), electrical machinery, chemical 
industry, etc.

It is logical to accept the perspective of A. Akayev and V. Sokolov, according to which developing a methodology of modeling strategies towards quantitative evaluations of structural changes is of strategic importance for the development of Russia's national economy (Akayev, 2013; Barashov, 2010).

Thus, assessing quality of sectoral and technological structures makes it possible to determine the nature of changes in the state of other macrosocial systems as well and their constituent parts (sectors and technological groups).

Advanced structural and technological shifts are hampered by the fact that the comprehensive modernization of the Russian economy should be implemented in challenging economic, geopolitical and social conditions. The global crisis makes it necessary to devise recommendations for improving the state structural and technological policies in Russia.

The cyclic component in the ongoing crisis prompts us to turn to the economic and technological retrofitting of the Russian economy as the most promising ways to overcome it.

It is possible to reverse the crisis only if there is a transition to an innovative, socially-oriented type of development of the whole macrosocial system rather and not only its individual subsystems.

Global instability brings about the need to examine the nature and causes of the crisis processes in order to contain them and develop strategies for sustainable national development at the institutional level.

We choose the institutional approach to study the nature of the crisis processes as a crisis of institutions in macrosocial systems, as the method allows us to explain the mechanism how a crisis is transferred from one system to others. Seem more on this in Enikeeva, Torosyan, 2012.

Figure 3 shows the classification of crises as crises of institutions.

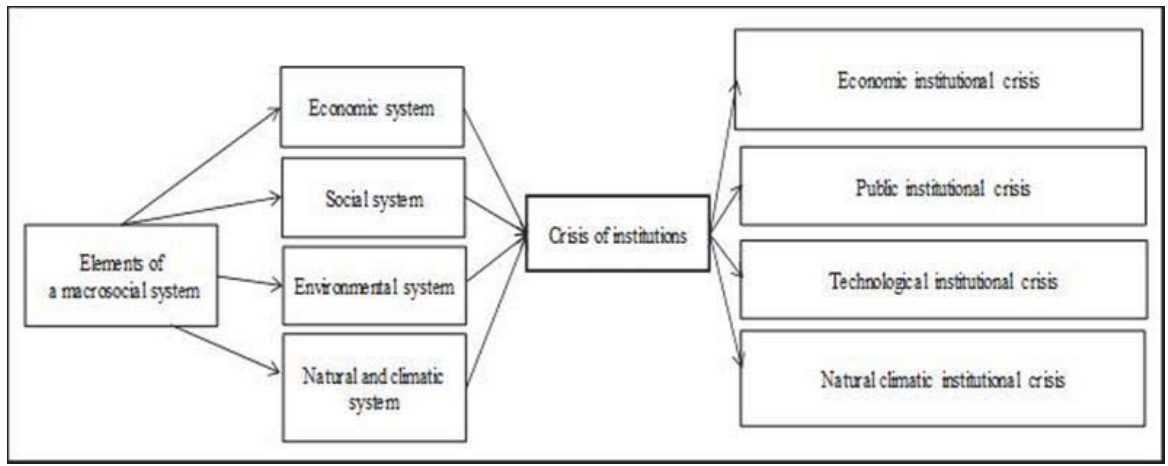

Figure 3. Classification of crises in a macrosocial system

We also point out that the globalization level reached by the moment is synchronizing to a large extent the economic development of all macrosocial systems incorporated in the single world system. In addition, interfaces of crisis phenomena in macrosocial systems still require further investigation. The fact is that crises are not contained in individual macrosocial systems, but are rapidly communicated to other systems, for example, in the form of crises of political institutions in the societal system (Egypt, Syria, Ukraine), financial crises of economic systems (Greece), crises of natural, climatic and environmental systems (Japan), etc.

A macrocrisis refers to crisis phenomena spanning over several macrosocial systems at a time. A microcrisis encompasses an individual macrosocial system. But it can also be contracted by other systems, so this division is rather arbitrary, as a crisis of institutions is diffused in systems. It then gives birth to global (world) and local crises.

A global (system wide) crisis spreads to all or most systems, local crises - on multiple systems or part of a system, and may stop growing further and evolve into a stagnation phase (Figure 4). Figure 4 shows the cyclic process of macrosocial systems transformation. 


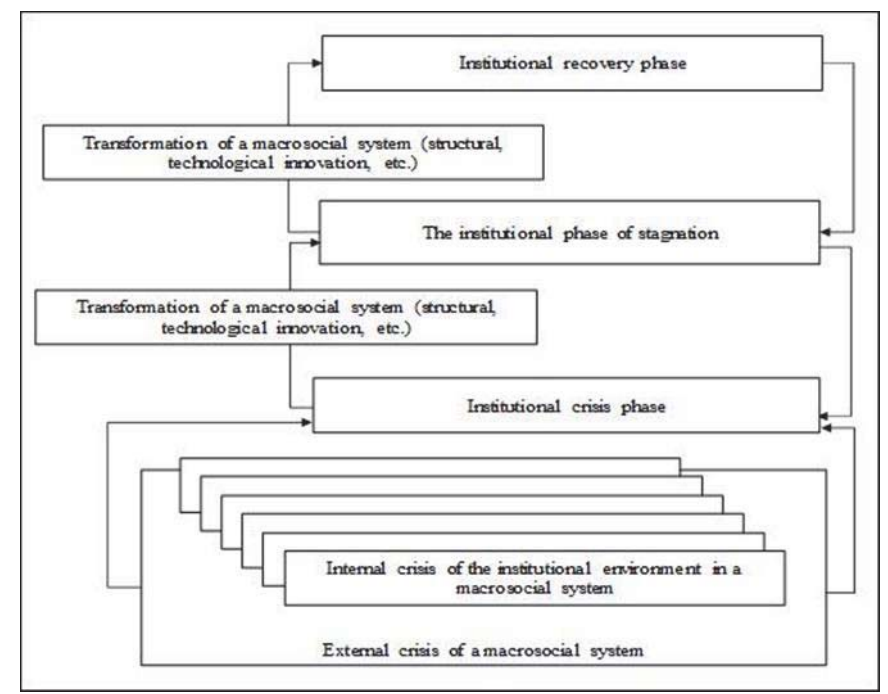

Figure 4. Cyclic process of transformation in macrosocial systems

The global crisis is a consequence of systemic instability in macrosocial systems. We propose defining world system resilience as maintaining a balance between the existence of various institutions (political, economic, social ones, etc.) in each macrosocial system so that it would help avoid severe crisis phenomena in any of these institutions.

The concept of an innovation development model for macrosocial systems includes not only material components of structural and technological innovation, but also non-material constituent parts of the resource potential, which affect the growth and welfare of the population:

- human capital as an aggregate of features possessed by individuals (various psychological characteristics, social status, cultural values, which, if preserved, will be a great advantage not only for people but also for the world as a whole) is the driving force behind the economic growth in the innovative development model of a macrosocial system;

- intellectual and information capital (intellectual property, knowledge capital);

- infrastructure capital which serves as a regulator for operating conditions of economic systems (smart, telecommunications and information technologies, methods and processes of management).

Of course, information and intellectual innovation spreads fast enough, if they are not hindered by artificial regulation attempts (e.g., sanctions on dissemination and implementation of new technologies).

Therefore, transformations in macrosocial systems in the form of innovation may become an efficient catalyst for long-term and sustainable economic growth of the entire system in the recovery phase, which is crucial for efforts to overcome the global instability of macrosocial systems.

\section{Acknowledgments}

Sources in the article have been research materials prepared under Russian Science Foundation grant No. 14-28-00065.

\section{References}

Akayev A.A, Sarygulov A.I. and Sokolov V.N., 2013. Structural changes in developed and developing economies. St. Petersburg. (In Russian).

Barashov N.G., 2010. Cyclic behaviors of structural and technological changes in the development of economic systems. Saratov. (In Russian).

Enikeeva L.A. and Torosyan E.K., 2012. A mechanism of crises transfer. ENGEC Vestnik, 3 (54): 54-61. (In Russian).

Martynov A.V., 2006. Transformation of macrosocial systems in the post-socialist world: a methodological aspect. Moscow. (In Russian)

Martynov S.N., 2002. New paradigms in the economic science. Novosibirsk. (In Russian).

Hayek F., 1991. The origin and effect of our morals: A problem for science. ECO, 12: 28-34. (In Russian). 